\title{
AN EXPERIMENTAL STUDY OF WATER FLOW IN SMOOTH AND ROUGH RECTANGULAR MICRO-CHANNELS
}

\author{
R. Baviere ${ }^{1,2}$, F. Ayela ${ }^{1}$, S. Le Person ${ }^{2}$ and M. Favre-Marinet ${ }^{2}$ \\ ${ }^{1}$ Centre de Recherches sur les Très Basses Températures, CNRS B.P. 166, 38042 Grenoble Cedex 09, France \\ ${ }^{2}$ Laboratoire des Ecoulements Géophysiques et Industriels, INPG, UJF, CNRS B.P. 53, 38041 Grenoble Cedex 09, France \\ Corresponding author : baviere@grenoble.cnrs.fr
}

\begin{abstract}
This paper presents experimental results concerning water flow in smooth and rough rectangular micro-channels. It is part of a work intended to test the classical fluid mechanics laws when the characteristic length scale of inner liquid flows falls below $500 \mu \mathrm{m}$. The method consists in determining experimental friction coefficients as a function of the Reynolds number. This implies simultaneous measurements of pressure drop and flow rates in microstructures. The two experimental apparatus used in this study enabled us to explore a wide range of length scales $(7 \mu \mathrm{m}$ to $300 \mu \mathrm{m})$ and of Reynolds number ( 0.01 to $8,000)$. Classical machining technologies were used to make micro-channels of various heights down to a scale of $100 \mu \mathrm{m}$. Smaller silicon-Pyrex micro-channels were also made by means of silicon-based micro technologies. In these structures, friction coefficients have been measured locally with $\mathrm{C}_{\mathrm{u}}-\mathrm{N}_{\mathrm{i}}$ strain gauges. For every height tested, both smooth and rough walls were successively used. When compared to macro-scale correlation the results demonstrate that i) In the smooth case, friction is correctly predicted by the Navier-Stokes equations with the classical kinematic boundary conditions, ii) For $200 \mu \mathrm{m}$ high channels, visualizations show transition to turbulence at Reynolds numbers of about 3,000. The presence of roughness elements did not significantly influence this result and iii) Roughness considerably increases the friction coefficient in the laminar regime. However, the Poiseuille number remains independent of the Reynolds number.
\end{abstract}

\section{INTRODUCTION}

Several fundamental studies have explored liquid flows in microstructures over the past 15 years. Many of these works have concluded to the existence of physical effects that could disrupt classical flow characteristics at microscales. Among the most mentioned effects, are those of roughness and of the Electrical Double Layer (EDL) at a solid/liquid interface, namely the electro-viscous effect. Nevertheless, considering the difficulties encountered in leading such experiments, it is not clear yet whether these effects are present or not. Published results are indeed questionable because of their very low level of reproducibility (Papaustky et al. 1999). In this paper, we present results obtained in well controlled experiments. These were designed to generate simultaneous pressure drop/flow rate measurements in micro-channels. Owing to the simplicity of the geometry, entrance effects and fully developed flow characteristics were clearly separated. These experiments were devoted to the determination of the influence of roughness elements on the characteristics (friction coefficient, laminar-turbulent transition) of liquid flows in micro-structures. In this objective, for each size explored, results in smooth and rough channels are compared. For all the experiments, the flow conditions were such that the electro-viscous effect could be neglected.

\section{Physics of liquids flowing in microstructures}

A comprehensive survey of the physics involved in liquid flows through microstructures $\left(D_{h}>1 \mu \mathrm{m}\right)$ was given by Gad-el-Hak (1999). The key points are as follows i) 
Simple liquid such as water can safely be treated as a continuous media, ii) The continuity of the velocity and temperature fields should remain valid at usual solid/liquid interfaces, as opposed to extremely non-wetting surfaces and iii) Low molecular weight liquids such as water, should reasonably have a newtonian behavior even for extremely high shear rates. The last two points were derived respectively from molecules dynamics calculation and from rheological considerations. It is therefore important to confirm these conclusions experimentally.

A physical phenomenon that could possibly influence pressure driven liquid flows in microstructures is the presence of an EDL at solid/liquid interface. This question has been studied 35 years ago, but has not yet been confirmed experimentally. This effect leads to an increased apparent viscosity of the fluid, and is therefore referred to as the electro-viscous effect. It was demonstrated for the first time by Burgreen and Nakache (1964). They showed that the relevant parameter for such flows is the electrokinetic radius which compares half of the hydraulic diameter of a channel to the Debye length of the liquid:

$$
r_{\text {elec }}=\frac{D_{h}}{2 \lambda_{D}}
$$

They have calculated that a necessary condition for the occurrence of a significant electro-viscous effect is that the electrokinetic radius be under 20. This limit corresponds to extremely dilute ionic solution in very narrow microchannel. A practical example of such flow is a $10^{-5} \mathrm{~mol}^{-1}$ KCL aqueous solution in a $2 \mu \mathrm{m}$ high non conducting slit, at room temperature. To our knowledge, only Ren et al. (2001) may have experimentally detected an electro-viscous effect for ultra deionized water flowing in a $14.1 \mu \mathrm{m}$ deep microchannel. The EDL effect was a priori negligible in our experiments. Nevertheless, ionic properties of the water used were controlled to be sure that they did not significantly influence the flow.

\section{A selection of published results in smooth and rough micro-channels}

The analysis of recent publications shows contradictory results. Qu et al. (2000) for instance, have experimentally investigated the characteristics of ultra-filtered deionized water flowing through an array of trapezoidal silicon-Pyrex micro-channels. For hydraulic diameters ranging from 51 to $169 \mu \mathrm{m}$, the results displayed a $30 \%$ rise of the friction coefficient compared to the classical laminar theory. This trend was interpreted as a roughness effect. The size of the roughness elements lying on the silicon engraved walls was estimated to be $0.8 \mu \mathrm{m}$ for the smallest channel and $2 \mu \mathrm{m}$ for the largest. Pfund et al. (2001) have studied the flow of filtered water in 2D polycarbonate/polyimide sandwiched micro-channels. No scale effect was found for the smooth case, but a $26 \%$ increase in the laminar friction coefficient was observed for a rough micro-channel $257 \mu \mathrm{m}$ in height. The roughness elements were estimated at around $1.8 \mu \mathrm{m}$. Recently, Judy et al. (2002) have studied liquids of different polarity flowing through fused silica and stainless steel capillaries of hydraulic diameter ranging from 15 to $150 \mu \mathrm{m}$. For distilled water, methanol and isopropanol, no scale effects were observed in the smooth tubes. For the rough stainless steel tubes, a classical Poiseuille number $P o$ versus Reynolds number $R e$ trend was observed in the laminar regime, but the value of $P o$ could only be determined within a $20 \%$ error margin. This inaccuracy is mainly due to the difficulty encountered during the measurement of the cross section of such tubes.

As can be seen from this review, it is not possible to conclude yet whether rough walls have significant effects on liquid laminar flows in microstructure. This question is very important, because of the predominance of laminar flow regimes in microstructures of inner scale smaller than $150 \mu \mathrm{m}$. The objective of this paper is to contribute to the understanding of the roughness effect. Therefore, we present experimental results concerning water flow in rectangular smooth and rough micro-channels. To explore a wide range of length scales, two types of micro-channels were built. The experimental data were interpreted as $P o$ versus $R e$ number evolution. Great care was taken to correctly take into account extremity losses and developing boundary layer effects. For the largest structures, the onset to turbulence was visualized by local injection of fluoresceine. In the smallest micro-channels, pressure was measured locally with integrated micro machined $\mathrm{C}_{\mathrm{u}}-\mathrm{N}_{\mathrm{i}}$ strain gauges.

\section{EXPERIMENTAL APPARATUS}

\section{Test sections}

The design goals for the experimental apparatus to investigate the characteristics of plane Poiseuille flow in micro-channels were: i) to have channels of large aspect ratios $(>80)$ and accurate dimensions, ii) to build compatible smooth and rough test sections to study the role of roughness elements on the flow and iii) to have some transparent walls in order to lead visualizations experiments.

The experimental apparatus designed for the study of channels with heights greater then $100 \mu \mathrm{m}$ consists of a closed-loop circuit which includes a pump (10 bars, 20 $1 \mathrm{~min}^{-1}$ ), a $1 \mu \mathrm{m}$ filter, two flowmeters (range $0.251 \mathrm{~min}^{-1}$ and $61 \mathrm{~min}^{-1}$ ), two pressure transducers (16 bars), a differential inductive pressure transducer $(0.1$ bars $)$, and two thermocouples type $\mathrm{K}$ for the determination of the inlet and outlet temperature. The signals from the different sensors were sampled by a data acquisition system KEITHLEY 2700 and stored in a pc microcomputer. Details on the experimental facility are given in Gao, Le Person and FavreMarinet (2002). 


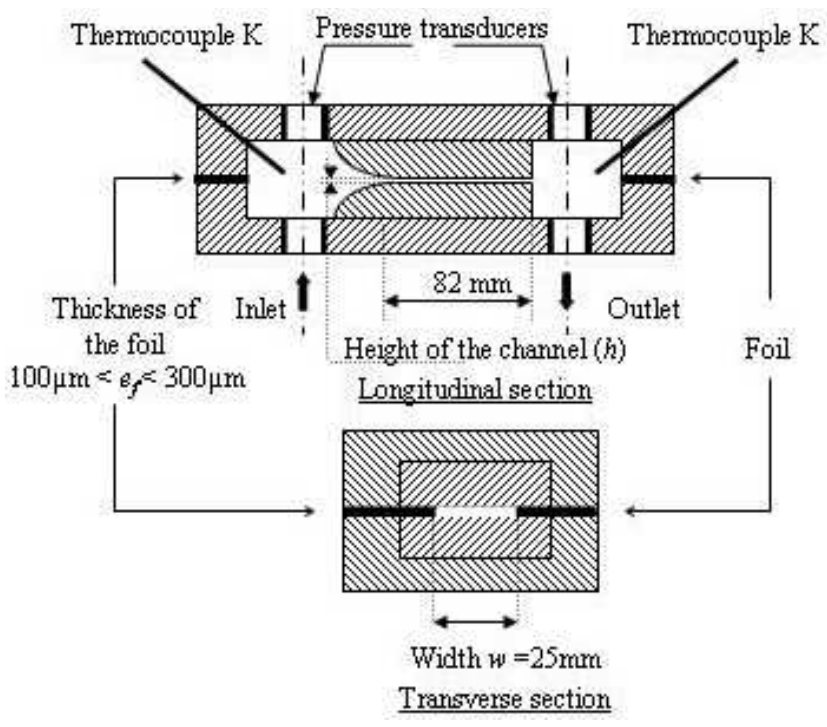

Fig. 1: Views of the foil-separated test sections $(h>100 \mu \mathrm{m})$.

The active channel walls are two smooth (arithmetical roughness $R a<0.1 \mu \mathrm{m}$ ) plane blocks, which are separated by a foil of thickness $e_{f}$, with a hollowed out central part of width $w$ equal to $25 \mathrm{~mm}$. Bronze and transparent Altuglas blocks were built in order to carry out visualizations. The test section is depicted in Fig. 1. After a first series of experiments, both bronze blocks were locally treated in order to obtain rough walls and to compare micro-flows in smooth and rough micro-channels. The local treatment consisted of an electrochemical deposition of a thin $\mathrm{N}_{\mathrm{i}}$ layer $\left(2 \mu \mathrm{m}\right.$ in depth), together with small $\mathrm{S}_{\mathrm{i}} \mathrm{C}$ particles (5 to $7 \mu \mathrm{m}$ in height), on both channel walls. A mask was used during the electro-deposition process to prevent roughening of the surfaces supporting the foils. The two $\mathrm{N}_{\mathrm{i}}+\mathrm{S}_{\mathrm{i}} \mathrm{C}$ films obtained were dried with a 10 bars nitrogen gas stream. Consequently, weakly anchored particles were removed before the series of hydrodynamic measurements, leaving some holes in the nickel layers. A schematic view of a foilseparated rough micro-channel is shown on Fig. 2.

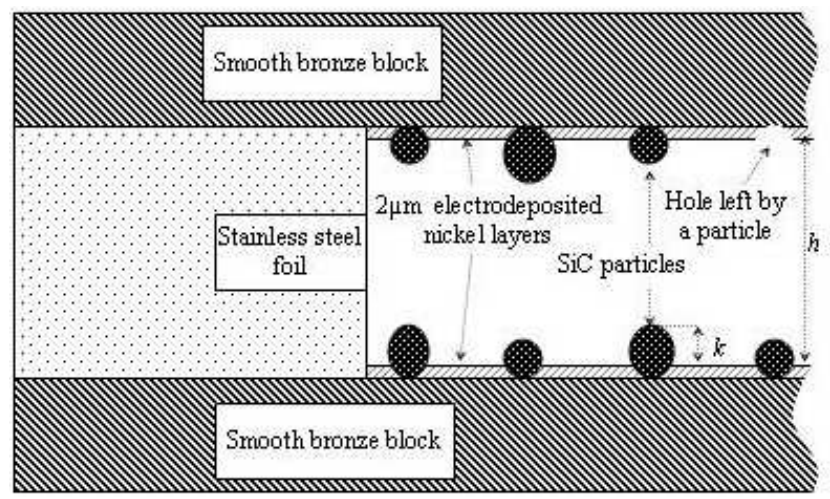

Fig.2: Transversal view of a foil-separated rough microchannel. The $h$ and $k$ parameters are defined in the text.
Below $100 \mu \mathrm{m}$, classical machining techniques become ineffective and it is necessary to use micro mechanical technologies to reach such small channel size. Well defined micro-channels down to a few microns in height can be constructed by this means. We have developed an original process to build silicon-Pyrex micro-channels equipped with integrated micro machined pressure transducers. The integrated probes provided local pressure measurements in a region where the flow is supposed to be fully developed. To our knowledge, it is the first attempt to perform local measurements in such small structures.

The manufacturing of these devices consists of four main steps: i) Two square $(3 \mathrm{~mm} \times 3 \mathrm{~mm})$ deflecting membranes of about $100 \mu \mathrm{m}$ in thickness are chemically etched with $\mathrm{KOH}$ at $80^{\circ} \mathrm{C}$ on a $15 \mathrm{~mm} \times 20 \mathrm{~mm}$ silicon substrate, ii) a $1 \mathrm{~mm}$ wide micro-channel and two $30 \mu \mathrm{m}$ wide connections to the membranes are reactively ion etched with $\mathrm{SF}_{6}$ or $\mathrm{SF}_{6} / \mathrm{O}_{2}$ plasma which provides respectively smooth and rough engraved walls, iii) a Pyrex cover is anodically bonded to the silicon sample in order to seal the channel and iv) $\mathrm{C}_{\mathrm{u}}-\mathrm{N}_{\mathrm{i}}$ strain gauges forming a Wheatstone bridge are sputtered on the back side of the deflecting membranes. A micrograph of the silicon substrate after steps i) and ii) can be seen on Fig. 3 .

Details on the micro fabrication principles, the characterization of the integrated pressure transducers and the calibration procedures can be found elsewhere (Baviere and Ayela (2004)). Typical sensitivity and mechanical resistance of the integrated probes are respectively $100 \mu \mathrm{V} \mathrm{V}^{-1}$ bar $^{-1}$ and 15 bar. The micro devices take place in an experimental loop composed of a high pressure expansion tank (up to 25 bar), a $0.45 \mu \mathrm{m}$ filter, a Pt 100 temperature probe, two lock-in amplifiers, a high precision pressure transmitter (Keller-33x, 30 bar, 0.025\%) for the strain gauges calibration procedures and a high precision balance (Kern-GS, $410 \mathrm{~g}, 0.001 \mathrm{~g}$ ). The instruments are connected to a microcomputer. Using the classical weighing method, we measured flow rates ranging from $210^{-6} 1 \mathrm{~min}^{-1}$ to $0.011 \mathrm{~min}^{-1}$.

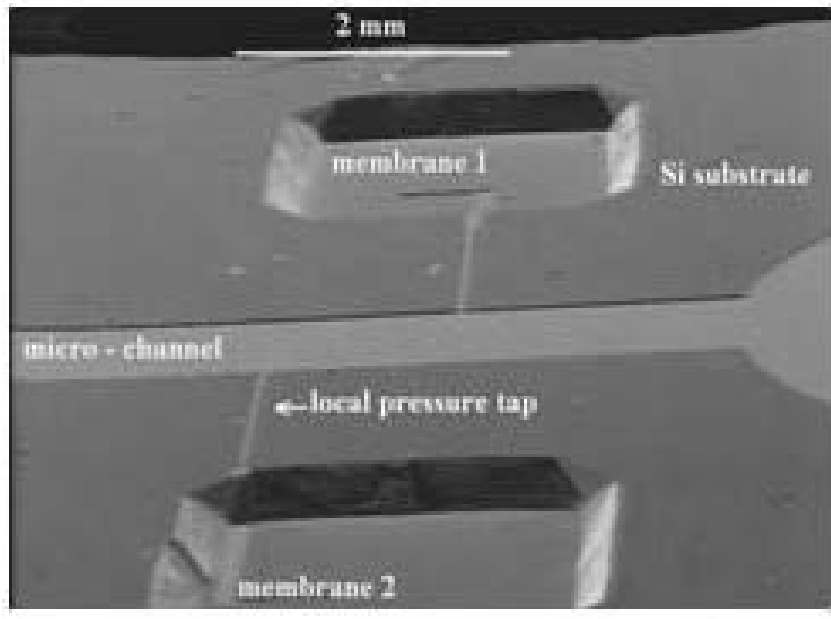

Fig.3: Micrograph of a silicon substrate with a rectangular $20 \mu \mathrm{m}$ high and $1 \mathrm{~mm}$ in width micro-channel connected to a pair of deflecting membranes. The distance between the two pressure taps is $1.5 \mathrm{~mm}$. 


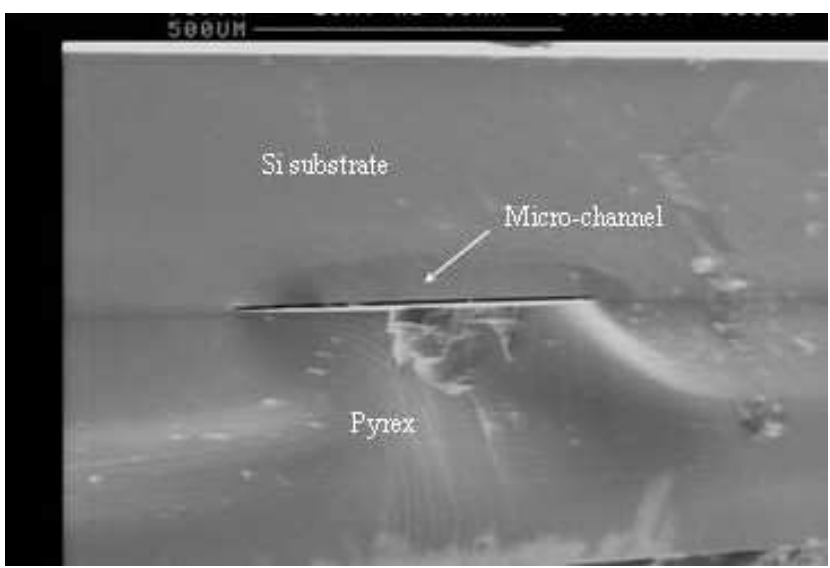

Fig. 4: SEM view of a $7.1 \mu \mathrm{m}$ deep, $1 \mathrm{~mm}$ wide silicon-Pyrex micro-channel.

Up to now, two samples have given interesting results. One is $7.5 \mu \mathrm{m}$ high and has smooth walls, whereas the second is $7.1 \mu \mathrm{m}$ high and has a rough silicon engraved wall and a smooth Pyrex wall. Another pair of samples of height $20 \mu \mathrm{m}$ is in preparation.

\section{Micro-channel depths and roughness}

Foil-separated micro-channels The sandwich version allowed to vary the channel depth by changing the thickness of the foil. The foil thicknesses were measured by a high precision comparator (digital MITUTOYO $0.001 \mathrm{~mm}$ Micrometer) at respective values of $100 \mu \mathrm{m}(+/-1 \mu \mathrm{m})$, $200 \mu \mathrm{m}(+/-1 \mu \mathrm{m})$ and $300 \mu \mathrm{m}(+/-1 \mu \mathrm{m})$. For the smooth case, the thickness of the foil gave directly the height of the channel. For the rough case, the channel height (parameter $h$ on Fig. 2) was deduced from the thickness of the foil by subtracting the total thickness of the electrodeposited nickel layers. This required a careful analysis of the surface finish.

It is a rather challenging task to characterize structures such as these rough surfaces. This is mainly due to the fact that micron-sized elements lay on a macro-sized block. In a first step we have analyzed top-view numerical photos of the rough surfaces taken through a Leica x200 microscope lens. These photos have revealed black dots on a clear background corresponding to the nickel layer. Typical planar extension of the dots ranges from 5 to $10 \mu \mathrm{m}$. The ratio of the surface occupied by black colored pixels to the total surface of the picture $(90 \mu \mathrm{mx} 120 \mu \mathrm{m})$ was estimated to be $37 \%$. Nevertheless, this estimation should be taken cautiously since dots on the picture represent holes as well as particles. This difficulty led us to complete the analysis with a $2 \mathrm{D}$ optical profilometer (Hommel Somicronic probe with a $30 \mathrm{~nm}$ vertical resolution, a $2 \mu \mathrm{m}$ planar resolution and $100 \mathrm{~mm}$ axial course). The probe used for the measurements was chosen for its very low level of sensitivity regarding the physical nature of the material which is analyzed. The topography measurements were done on completion of the series of hydrodynamic measurements in several different locations of the test section. The $\mathrm{N}_{\mathrm{i}}+\mathrm{S}_{\mathrm{i}} \mathrm{C}$ rough films have been found to be transversally uniform through the whole width of the channels $(w=25 \mathrm{~mm})$. In each case, these measurements have revealed well marked step like profiles between the smooth bronze substrate and the rough $\mathrm{N}_{\mathrm{i}}+\mathrm{S}_{\mathrm{i}} \mathrm{C}$ surfaces. The thickness of the nickel layers was determined to be $2 \mu \mathrm{m}(+/-0.5 \mu \mathrm{m})$ for both sides. This value is in good agreement with that deduced from the characteristics (time and current intensity) of the electrochemical deposition. Another interesting finding is that for all the measurements, the maximum height between the nickel layer and the top of a particle (parameter $k$ on Fig. 2) was measured to be slightly over $5 \mu \mathrm{m}$. The distance between two successive holes or roughness elements was found to be around $15 \mu \mathrm{m}$ along each line analyzed. This value is in rough agreement with that obtained by the photo analysis.

Silicon-Pyrex micro-channels Silicon-Pyrex micro-channel depths were measured in two ways. Before the bonding of the Pyrex cover, a Tencor profilometer determined the engraved depth of the silicon substrate. This measurement was confirmed by post-mortem analysis of the transverse cross-section of the device. The silicon-Pyrex ensemble was cleaved, sputter-coated with a few nanometers of gold and inspected in a scanning electron microscope (SEM). Figure 4 shows a typical SEM view obtained in this manner. This verification ensures that the geometry of the channel is not affected by the anodic bonding operation. For smooth channels, both methods yielded similar results, but for rough engraved silicon walls, the mechanical profilometer was rather inaccurate. This is because the diameter of its tip $(5 \mu \mathrm{m})$ was big compared to the characteristic length scale of the roughness elements. In that case, only SEM measurements were used to determine the depth of the channel. Nevertheless, even this method was rather inaccurate for randomly shaped and spaced roughness elements obtained from $\mathrm{SF}_{6} / \mathrm{O}_{2}$ plasma etching.

Table 1 gives a summary of the geometrical characteristics of the different rectangular channels tested in this work. The $h$ parameter is the distance between the baselines of the surfaces (see Fig. 2). It should be noticed that for rough surfaces, this parameter does not represent the passage area of the channel. The $k$ parameter gives the elevation of the top of a roughness element counted from the baseline of the surface. The $\lambda$ parameter gives the planar spacing of the roughness elements. The SP-2* channel was obtained from a $\mathrm{SF}_{6} / \mathrm{O}_{2}$ plasma etching process. As explained above, the determination of $h$ was difficult in that case.

\section{Experimental procedure}

A practical way to obtain estimation for the Debye length of a dilute solution is to measure its conductivity. The water used for the foil-separated experiments was filtered before entering the microstructure. Its conductivity was measured to be $300 \mu \mathrm{S} \mathrm{cm}^{-1}$ at $20^{\circ} \mathrm{C}$. This high value is close to that of common tap water. For the silicon-Pyrex type 
Table 1: Geometrical characteristics of the micro-channels

\begin{tabular}{|c|c|c|c|c|c|c|c|}
\hline Sample & $h(\mu m)$ & Wall 1 / Wall 2 & $L(\mathrm{~mm})$ & $w(m m)$ & $k(\mu m)$ & Shape & $\lambda(\mu m)$ \\
\hline FS-1 & $300(+/-1)$ & Bronze / Bronze & 82 & 25 & $<0.1$ & & \\
\hline FS-2 & $200(+/-1)$ & Bronze / Bronze & 82 & 25 & $<0.1$ & & \\
\hline FS-3 & $200(+/-1)$ & Altuglas / Altuglas & 82 & 25 & $<0.1$ & & \\
\hline FS-4 & $100(+/-1)$ & Bronze / Bronze & 82 & 25 & $<0.1$ & & \\
\hline SP-1 & $7.5(+/-0.2)$ & $\mathrm{S}_{\mathrm{i}} /$ Pyrex & 6 & 3 & $<0.05$ & & \\
\hline FS-5* & $296(+/-2)$ & $\mathrm{N}_{\mathrm{i}}+\mathrm{S}_{\mathrm{i}} \mathrm{C} / \mathrm{N}_{\mathrm{i}}+\mathrm{S}_{\mathrm{i}} \mathrm{C}$ & 82 & 25 & 5 & Particle & $\sim 30$ \\
\hline FS-6* & $198(+/-1.5)$ & $\mathrm{N}_{\mathrm{i}}+\mathrm{S}_{\mathrm{i}} \mathrm{C} /$ Altuglas & 82 & 25 & $5 /<0.1$ & Particle / ----- & 230 / ----- \\
\hline FS-7* & $196(+/-2)$ & $\mathrm{N}_{\mathrm{i}}+\mathrm{S}_{\mathrm{i}} \mathrm{C} / \mathrm{N}_{\mathrm{i}}+\mathrm{S}_{\mathrm{i}} \mathrm{C}$ & 82 & 25 & 5 & Particle & $\sim 30$ \\
\hline FS-8* & $96(+/-2)$ & $\mathrm{N}_{\mathrm{i}}+\mathrm{S}_{\mathrm{i}} \mathrm{C} / \mathrm{N}_{\mathrm{i}}+\mathrm{S}_{\mathrm{i}} \mathrm{C}$ & 82 & 25 & 5 & Particle & $\sim 30$ \\
\hline SP-2* & $7.1(+/-0.4)$ & $\mathrm{S}_{\mathrm{i}} /$ Pyrex & 6 & 1 & $0.75 /<0.05$ & Pyramid / ----- & 〜 / ----- \\
\hline
\end{tabular}

experiments, demineralized water was used as the working fluid. Despite a very clean experimental loop and an expansion tank that avoided contact between atmospheric gases and the working fluid, we noticed ionic pollution of the water during the experiments. Its conductivity at $20^{\circ} \mathrm{C}$ was measured to be $7 \mu \mathrm{S} \mathrm{cm}^{-1}$ in the expansion tank and $10 \mu \mathrm{S} \mathrm{cm}^{-1}$ in the collecting reservoir at the other end of the experimental apparatus. We therefore assumed a conductivity of $8.5+/-1.5 \mu \mathrm{S} \mathrm{cm}{ }^{-1}$ in the silicon-Pyrex micro-channels.

The Debye length of a liquid is related to its ionic composition as follows:

$$
\lambda_{D}=\sqrt{\frac{k_{B} T \varepsilon \varepsilon_{o}}{e^{2} \sum_{i} n_{i} z_{i}{ }^{2}}}
$$

Here, $k_{B}$ is the Boltzmann's constant, $T$ is the absolute temperature, $e$ is the electron charge, $n_{i}$ and $z_{i}$ are respectively the concentration and the valence of the type $i$ ions and $\mathcal{E}, \varepsilon_{o}$ are the dielectric constant of the solvent and the dielectric permittivity of vacuum. In dilute aqueous solutions, it can be assumed that conductivity is proportional to ionic concentration. As a reference, pure water composed of $10^{-7} \mathrm{~mol} \mathrm{l}^{-1}$ of $\mathrm{H}_{3} \mathrm{O}^{+} / \mathrm{OH}^{-}$has a conductivity of $0.04 \mu \mathrm{S} \mathrm{cm}^{-}$ ${ }^{1}$ at $20^{\circ} \mathrm{C}$. This leads to a specific conductivity of $410^{5} \mu \mathrm{S}$ $\mathrm{cm}^{-1} /\left(\mathrm{mol} \mathrm{l}^{-1}\right)$ for the $\mathrm{H}_{3} \mathrm{O}^{+} / \mathrm{OH}^{-}$couple. Considering that the $8.5 \mu \mathrm{S} \mathrm{cm}^{-1}$ water used in the silicon-Pyrex micro-channels is exclusively composed of monovalent ionic species of specific conductivity equal to that of the $\mathrm{H}_{3} \mathrm{O}^{+} / \mathrm{OH}^{-}$couple, it is possible to deduce from the conductivity measurement, an equivalent ionic concentration. This gives a $2.110^{-5} \mathrm{~mol} \mathrm{l}^{-}$ ${ }^{1}$ value. When used in Eq. (2), it leads to $75 \mathrm{~nm}$ which is an overestimation of the Debye length. Consequently, the smallest electrokinetic radius encountered in our experiments is over 95 for the SP-2* micro-channel. According to the criteria concerning the electro-viscous effect, this estimation demonstrates that the EDL effect can safely be neglected in our experiments.
Experimental results reported in this paper were repeated to verify their reproducibility. This is particularly important for the channels with $\mathrm{N}_{\mathrm{i}}+\mathrm{S}_{\mathrm{i}} \mathrm{C}$ surfaces for which the flow could have removed particles. Fortunately, the tests have shown that the friction's characteristics were repeatable, which indirectly demonstrated the robustness of the particles anchorage. For the silicon-Pyrex devices, air was vacuumed out of the microsystem before the water filling operation. This prevented gas from being trapped in the pressure probe cavities and in the chinks in between roughness elements. At the exit of the silicon-Pyrex microsystems, a set of ultra-fine capillaries were used to vary the pressure level of the ensemble between different experiments. Results were found to be independent this operation. This indicates that the $\mathrm{C}_{\mathrm{u}}-\mathrm{N}_{\mathrm{i}}$ pressure probes work correctly, that the height of the channels is not affected by the pressure level (up to 25 bar) and that gas blanket phenomena, as suggested by Sabry (2000), do not occur in such flows.

To measure very low flow rates with the weighting method, two main precautions were taken. Firstly, the delivery needle supplying the weighted reservoir was immersed under the water level in order to avoid capillary instabilities. Secondly, the weighted reservoir was covered with a finely pierced latex sheet to limit evaporation of water. As a consequence, we have measured a steady state evaporation rate of $10^{-7} 1 \mathrm{~min}^{-1}$ that is small compared to the smallest flow rate of this study $\left(210^{-6} 1 \mathrm{~min}^{-1}\right)$.

The Reynolds number $R e$ of the flow is based on the hydraulic diameter and the bulk velocity across the channel. The physical properties of water were determined with the average inlet-outlet temperature in the foil separated microchannels and with the outlet temperature for the siliconPyrex micro-channels. The friction coefficient was calculated from the measured pressure drop. For the foil separated micro-channels, inlet pressure was corrected for the inertia term accounting for flow acceleration of the fluid in the converging channel entrance. The friction coefficient can be expressed as: 


$$
f=\frac{\tau}{\frac{1}{2} \rho U^{2}}=\frac{\Delta P D_{h}}{2 \rho U^{2} L}
$$

For the fully developed laminar regime in conventional channels, Eq. (3) can be written:

$$
f=\frac{24}{R e} \quad \text { or } \quad P o=f . R e=24
$$

As can be deduced from Eqs. (3) and (4), the Po number depends on $h^{3}$. Consequently, the inaccuracy in the evaluation of the $h$ parameter is the major source of error in the determination of $P o$.

For the hydraulically smooth turbulent regime, comparison can be made with the Blasius law:

$$
f=\frac{0.079}{R e^{1 / 4}} \quad \text { or } \quad \text { Po }=0.079 R e^{3 / 4}
$$

The hypothesis of the fully-developed regime is valid only after the entrance region. Equation (4) should therefore be modified for interpreting the results obtained from inlet/outlet pressure measurements. Using $L^{+}=L /\left(\operatorname{Re} D_{h}\right)$, Shah and London (1978) proposed a modified law for the laminar regime:

$$
P o=\frac{3.44}{\sqrt{L^{+}}}+\frac{24+\frac{0.674}{4 L^{+}}-\frac{3.44}{\sqrt{L^{+}}}}{1+\frac{0.000029}{L^{+2}}}
$$

In the turbulent regime, the extension of the entrance region is about $10 D_{h}$ so that the Blasius law is relevant for the present channels.

\section{RESULTS AND DISCUSSION}

Figure 5 shows the evolution of the $P o$ number as a function of the $R e$ number for the smooth channels tested. For sake of clarity, error bars have only been drawn for the most severe case, i.e. the SP-1 channel. These error bars reflect the uncertainty in the evaluation of the parameter $h$. For $R e$ below 1000, the $P_{O}=24$ classical law is well verified for all the heights tested. Therefore, we find that the NavierStokes equations and the no slip boundary condition are verified in the conditions of our experiments. These conclusions are opposite to those drawn by Brutin and Tadrist (2003), who found a scale effect on water flowing through smooth micro tubes of diameter smaller than $250 \mu \mathrm{m}$. To separate entrance effects from onset to turbulence effects, the results concerning FS-1 and FS-2

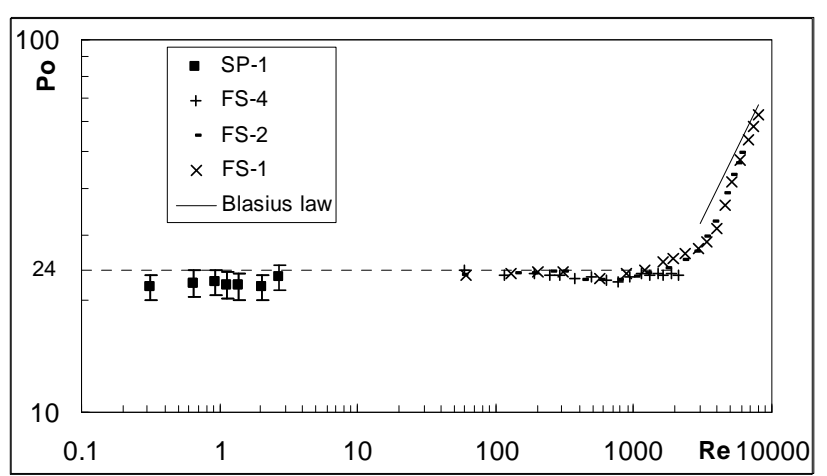

Fig. 5: Influence of the height of the channel on the Po number: the smooth case.

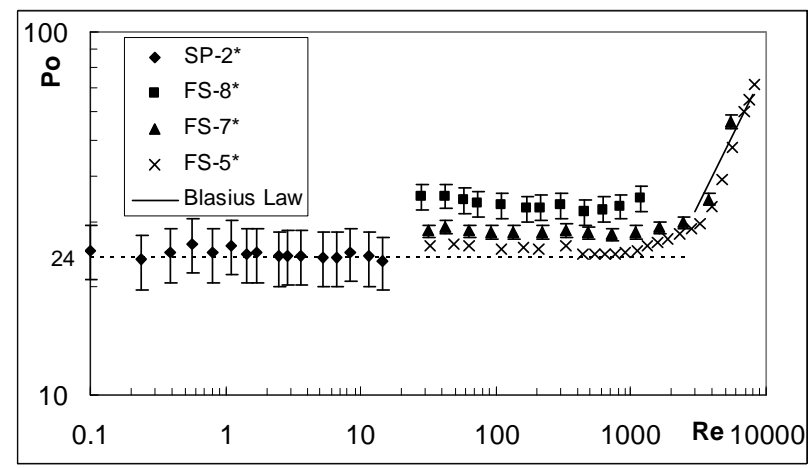

Fig. 6: Influence of roughness on the laminar regime of micro-flows. Geometrical characteristics of the microchannels and roughness elements are listed in table 1.

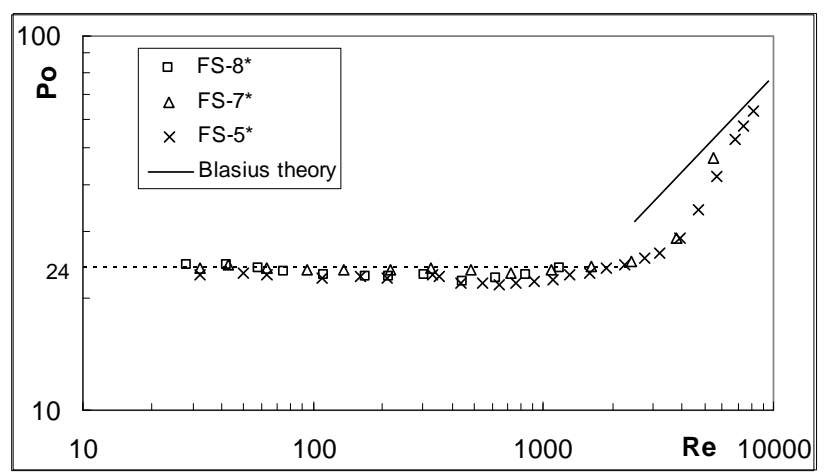

Fig. 7: Experimental data from the $\mathrm{N}_{\mathrm{i}} / \mathrm{S}_{\mathrm{i}} \mathrm{C}$ rough channels calculated with a reduction of $11 \mu \mathrm{m}$ in the parameter $h$.

channels were analyzed with the $L^{+}$parameter and compared to Eq. (6) (Gao et al., 2002). This analysis confirmed the previous finding. The onset to the turbulent regime was visualized in the transparent FS-3 channel by a classical dye injection system. Further details on this 
experiment are given later. Onset to turbulence was detected at $R e$ about 3000 .

Figure 6 shows the evolution of the Po number as a function of the $R e$ number for rough channels. The error bars are particularly large for the SP-2* channel. This is again due to the difficulty encountered for the determination of the $h$ parameter in this channel. The curves $P o(R e)$ show the usual trend, i.e. a constant $P o$ number in the laminar regime. A striking feature is that the values of $P o$, when calculated with $h$, are seriously underestimated by the $P O=24$ law for FS-5*, FS-7* and FS-8*. For Re between 50 and 1000 , the relative deviation for the three channels is respectively $37 \%, 17 \%$ and $5 \%$. It is interesting to notice that the data concerning these three channels collapse on the $P_{O}=24$ curve (Fig. 7) if calculated with a reduction of $11 \mu \mathrm{m}$ in $h$. This means that the same pressure drop in the laminar regime would occur in equivalent smooth channels of smaller channel height.

The correction can be interpreted as the presence of two stagnant $5.5 \mu \mathrm{m}$ wall layers. The $5.5 \mu \mathrm{m}$ value is very close to the $k$ parameter of these channels. In other words, laminar recirculating flows probably occur behind each element and produce a quasi-total blockage effect. These recirculating structures have been numerically calculated by $\mathrm{Hu}$ et al. (2003), for liquid flows in 2-D micro-channels with rectangular prism rough elements. These calculations revealed stagnant liquid zones between the elements. Their main effect is to reduce the effective cross-sectional area of the channel so an expression of the relative channel height reduction as a function of the roughness elements height, size, spacing and channel height was given. Unfortunately, this expression is not adapted to channels FS-5*, FS-7* and FS-8* and can consequently not be tested. For the four decade $R e$ range (0.001 to 10 ) explored by Hu et al. (2003), the $P o$ number has been found to be a constant for all the channels of the computation. This numerical finding is very well verified in all our experiments contrary to those of Mala et al. (1999).

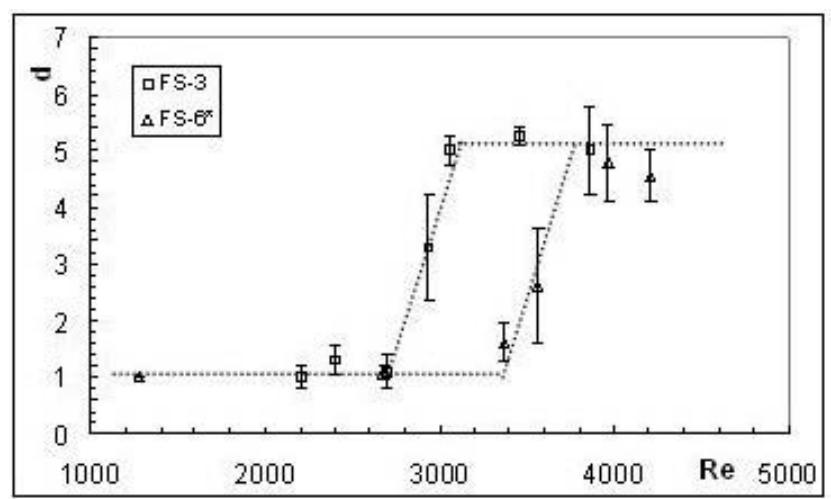

Fig. 8: dimensionless exit width of the streak as a function of $R e$ number around onset to turbulence. The square and the triangle plots correspond respectively to a smooth and a rough micro-channel of around $200 \mu \mathrm{m}$ in height.
Micro-flows were visualized in micro-channels with smooth and rough walls (respectively FS-3 and FS-6*). The transparent Altuglas blocks were used in order to observe a streakline colored by fluoresceine. Dye was injected with a needle at the local velocity of water in the channel entrance region. The size and shape of the colored filament near the channel exit were recorded with a numerical camera associated with a long distance microscope. The observations have revealed very stable flows for $R e$ number up to 2500 for both the smooth FS-3 channel and the rough FS-6* channel. On the contrary, large eddies were visualized for $R e$ number over 3800 . For fixed $R e$ number between 2500 and 3 500, stable flow region following turbulent spots were observed.

The width of the streak at the exit of the channel was measured as a function of $R e$. The ratio of the exit width to that in the entrance region gives the dimensionless width $d$ of the streak. Figure 8 shows the $d(R e)$ curves obtained for the FS-3 and FS-6* channels. The aperture time of the camera was chosen to be important compare to the convective time of the flow based on the bulk velocity and on the width of the picture.

Both micro-channels used for the visualizations, have an aspect ratio of 125 . It should be mentioned that very few experiments results are available for plane Poiseuille flows. Moreover, transition is suspected to be very sensitive to inlet geometries. Our results will therefore only be compared to those of Carlson, Widnall and Peeters (1982). They studied transition in a $6 \mathrm{~mm}$ in height, $800 \mathrm{~mm}$ wide smooth Plexiglas channel (aspect ratio of 133). Their smooth inlet contraction can be compared to the entrance region of our foil-separated micro-channels. It should be noticed that their experimental facility provided very low background turbulence effects. In our experimental loop, this latest parameter was not controlled. At a Reynolds number of 2700 , they report that growing turbulent spots could be artificially triggered. These generated spots were not sensitive to disturbance amplitude. At Reynolds numbers above 3 200, natural turbulent spots appeared randomly in their channel. Finally, fully turbulent flow fields were observed for Reynolds numbers above 4000.

Figure 8 gives an objective way to locate the beginning of turbulence in our channels. The results reveal a 500\% growth of the $d$ parameter in a 400 wide Re number interval. Transitional flows were obtained in the smooth FS-3 microchannel for Re numbers between 2700 and 3100 . These values are consistent with those reported by Carlson et al. (1982) in a macro-scale channel. For the rough FS-6* micro-channel, transitional flows were obtained for $R e$ numbers between 3400 and 3800 . This indicates that roughness elements produce a stabilizing effect for such flows. This surprising result cannot be explained.

The conclusions that can be drawn from this study is that for a smooth $200 \mu \mathrm{m}$ channel, turbulence appears at $R e$ values very close to that observed in conventional sized channel. Secondly, roughness elements do not reduce the transitional Re number in micro-channels $200 \mu \mathrm{m}$ in height. 


\section{CONCLUSION}

Well controlled pressure drop/flow rate measurements have been performed in a variety of rectangular microchannels. Filtered and demineralized water was used as the working fluid. Silicon based micro technologies are necessary to build the smallest structures. The effect of wall roughness elements has been investigated. The key results of this paper can be formulated as follows:

1. Well controlled experiments have proved that friction was correctly predicted by the classical Navier-Stokes equations and boundary conditions. No scale effect was found for water in rectangular smooth microchannels of height ranging from $7 \mu \mathrm{m}$ to $300 \mu \mathrm{m}$. The transitional $R e$ number is in agreement with that of macro-scale flows.

2. The electro-viscous effect has been found to be negligible in our flow conditions.

3. Natural and artificial wall roughness elements have not disrupted the independence of the Po number from the $R e$ number in the laminar regime.

4. Roughness elements induce hydrodynamic dead zones near the wall giving rise to a significant enhancement of the friction coefficient. Their extension has been determined to be very close from the roughness elements height.

5. Roughness elements do not lower the transitional Reynolds number for such flows. On the contrary, we found that such elements produce a retarding effect for the onset to turbulence.

\section{NOMENCLATURE}

$d$ dimensionless width of the dye streak, dimensionless

$D_{h}$ hydraulic diameter,

$e$ electron charge,

ef thickness of the foil,

$k$ height of a roughness element,

$k_{B} \quad$ Boltzmann constant,

$h$ height of the channel,

$L \quad$ length,

$L^{+} \quad$ dimensionless channel length,

$n \quad$ ionic concentration, molecule

$P \quad$ static pressure,

$P o$ Poiseuille number,

$r_{\text {elec }}$ electrokinetic radius,

$R a$ arithmetical roughness,

Re Reynolds number,

$T$ temperature,

$U$ channel bulk velocity,

$w \quad$ width of the channel,

$z \quad$ electric charge in electron,

\section{Greek symbols}

$\varepsilon \quad$ dielectric constant of a solvent,

$\varepsilon_{o} \quad$ dielectric permittivity of vacuum, $\lambda$ roughness element spacing,

$\mathrm{m}$

$\lambda_{D}$ Debye's length,

$\rho$ volumic mass,

$\tau \quad$ wall shear stress,

$\mathrm{m}$

$\mathrm{kg} \mathrm{m}^{-3}$

$\mathrm{N} \mathrm{m}^{-2}$

\section{REFERENCES}

Baviere, R., and Ayela, F., 2004, Micromachined strain gauges for the determination of liquid flow friction coefficients in microchannels, Measurements science and Technology, Vol. 15, pp 377-383.

Brutin, D., Tadrist, L., Experimental friction factor of a liquid flow in microtubes, 2003, Physics of Fluids, Vol. 15, no. 3, pp 653-661.

Burgreen, D. and Nakache, F.R., 1964, Electrokinetic Flow in Ultrafine Capillary Slits, J. of Physical Chemistry, Vol. 68, no. 5, pp 1084-1091.

Carlson, D. R., Widnall, S. E. and Peeters, M. F., 1982, A flow-visualization study of transition in plane Poiseuille flow, J. Fluid Mech., Vol. 121, pp 487-505.

Gad-el-Hak, M., 1999, The Fluid Mechanics of Microdevices, J. of Fluids Engineering, Vol. 121, pp 7-33.

Gao, P., Le Person, S., Favre-Marinet, M., 2002, Scale effects on Hydrodynamics and Heat Transfer in two dimensional mini and microchannels, Int. J. of Thermal Sciences, Vol. 41, pp 1017-1027.

Hu, Y., Werner, C., Li, D., 2003, Influence of ThreeDimensional Roughness on Pressure-Driven Flow Through Microchannels, Journal of Fluids Engineering, Vol. 125, pp 871-879.

Judy, J., Maynes, D., and Webb, B. W., 2002, Characterization of frictional pressure drop for liquid flows through microchannels, Int. J. Heat and Mass Transfer, Vol. 45, pp 3477-3489.

Mala, Gh., M. and Li, D. 1999, Flow characteristics of water in microtubes, Int. J. of Heat and Fluid Flow, Vol. 20, pp 142-148.

Papautsky, I., Brazzle, J., Ameel, T., Frazier, B., 1999, Laminar fluid behavior in microchannels using micropolar fluid theory, Sensors and Actuators, Vol. 73, pp 101-108.

Pfund, D., Rector, D., Shekarriz, A., Popescu, A., and

dimensionless $\mathrm{m}^{-3}$

$\mathrm{Pa}$

dimensionless dimensionless $\mathrm{m}$ dimensionless $\mathrm{K}$ $\mathrm{m}$

dimensionless Welty, J., 2000, Pressure Drop Measurements in a Microchannel, AIChE Journal, Vol. 46, No. 8, pp 14961507.

Qu, W., Mala, G. M., and Li, D., 2000, Pressure driven water flows in trapezoidal silicon microchannels, Int. J. of Heat and Mass Transfer, Vol. 43, pp 353-364.

Ren, L., Qu, W. and Li, D., 2001, Interfacial electrokinetic effects on liquid flow in microchannels, Int. J. of Heat and Mass Transfer, Vol. 44, pp 3125-3134.

Sabry, M.N., 2000, Scale effects on fluid flow and heat transfer in micro channels, IEEE Transactions on components and packaging Technologies 2000, Vol. 23-3, pp 562-567.

Shah, R.K., London, A.L., 1978, Laminar forced convection in ducts, Advanced heat transfer, Academic press New-York. 